http://jmscr.igmpublication.org/home/

ISSN (e)-2347-176x ISSN (p) 2455-0450

crossref DOI: https://dx.doi.org/10.18535/jmscr/v7i7.170

Journal Of Medical Science And Clinical Research

\title{
A study to analyse the potentiality of Serum Uric Acid to use as a biomarker to detect Essential Hypertension Severity
}

\author{
Authors \\ Dr Mritunjay Kumar ${ }^{*}$, Dr Smriti Kumari \\ ${ }^{1}$ Assistant Professor, Department of Medicine, Narayan Medical College and Hospital, Sasaram, Bihar, \\ India \\ ${ }^{2}$ Department of Microbiology, Darbhanga Medical College and Hospital, Darbhanga, Bihar, India \\ *Correspondence Author \\ Dr Mritunjay Kumar
}

Assistant Professor, Department of Medicine, Narayan Medical College and Hospital, Sasaram, Bihar, India

\begin{abstract}
Aim: It has been seen that two third of patient who were having elevated blood pressure also unaware regarding their condition and as a result develop further complication. In a state like Bihar there was a need to correlate with a blood biomarkers which shed light on the underlying processes involved in the onset, development, and progression of essential hypertension. To analyse the potentiality of Serum uric acid to use as a biomarker to detect essential Hypertension Severity

Material: This was a single centre study. Total 120 patients were included in this trial where 60 subjects were with essential hypertension and rest 60 patients were without essential hypertension. This study was conducted at Diabetes centre in Bihar. Blood pressure was measured by a sphygmomanometer (Brand name Diamond) and pathological blood test was conducted at single NABL accredited pathology laboratory. Consent was taken from each participant. Current study was performed in accordance with the declaration of Helsinki.

Result: Subjects with essential hypertension also having high mean serum uric acid of $6.8 \pm 2 \mathrm{mg} / \mathrm{dl}$ where as it was normal i.e. $4.2 \pm 0.2 \mathrm{mg} / \mathrm{dl}$ with control subjects who were not having any grade of hypertension ( $p \leq 0.005)$. It was observed that even duration of HTN is effect the level of serum uric acid. Subjects who were having HTN for more than 5 years were having serum uric acid of $7.1 \pm 0.3 \mathrm{mg} / \mathrm{dl}$ whereas subjects who were having HTN for less than 5 years were having serum uric acid of $4.5 \pm 0.2 \mathrm{mg} / \mathrm{dl}$.

Conclusion: Serum uric acid can be used as a biomarker to detect essential hypertension severity and duration.

Keywords: Hypertension, uric acid, biomarker, severity and duration.
\end{abstract}

\section{Introduction}

In south Asia, one of the most important risk factor for attributable burden of disease is high blood pressure (BP) or essential Hypertension $(\mathrm{HTN})^{[1]}$. Especially in India, HTN is one the major cause of cardio vascular events and death 
related to cardiovascular disease ${ }^{[2,3]}$. In India almost 57\% death due to stroke and 24\% death due to coronary heart disease (CHD) is directly responsible for immerging prevalence of $\mathrm{HTN}^{[4]}$. Even WHO (World Health Organization) has already considered HTN as one the main cause of deaths in worldwide ${ }^{[5]}$. The rates for HTN in percentage are projected to go up to 22.9 and 23.6 for Indian men and women, respectively by 2025 [6].

Biomarkers are objective, quantifiable characteristics of biological processes, which can be measured accurately and reproducibly ${ }^{[7]}$. They may or may not necessarily correlate with patient's clinical symptoms. Clinical endpoints, on the other hand, represent a study subject's health and wellbeing from the subject's perspective. Some specific biomarkers, however, have been well characterized and repeatedly shown to correctly predict relevant clinical outcomes across a variety of disease treatments and affected populations. Overt HTN is preceded by abnormalities in multiple biological pathways ${ }^{[8]}$. It is thus plausible that biomarkers involved in these multi-pathway abnormalities in normotensive or pre-hypertensive patients could foretell the increased risk of HTN. Studies have shown that pharmacological treatment of patients with prehypertension can delay the onset of $\operatorname{HTN}^{[9,10]}$.

Even though the actual mechanism by which increasing uric acid effects cardiovascular system or end organ is still not clear, it was postulated that the effect of uric acid in endothelial dysfunction may responsible for its high impact on cardiovascular system.

The main purpose of this study is to analyse the potentiality of Serum Uric Acid to use as a biomarker to detect in Essential Hypertension Severity.

\section{Methods}

Total 120 patients were included in this trial where 60 subjects were with essential hypertension and rest 60 patients were without essential hypertension. This study was conducted at private clinic in Bihar. A written consent was collected from the subjects and the study was approved by Institutional ethical committee. Consent was taken from each participant. Current study was performed in accordance with the declaration of Helsinki.

Subjects whose age was in between $30-70$ years without any cardiovascular events and visited to the out patients department were included in the study. Subjects were excluded who were having abnormally raised serum uric acid and renal failure.

Hypertension was detected as per JNC VIII and measured by sphygmometer (Diamond BPMR112 Aneroid Blood Pressure Monitor, India). Serum uric acid was measured by kit method on ERBA XL-640 Fully Automated Analyser and conducted at single NABL accredited pathology laboratory. Data was arranged in MS Excel. Student's t test was used to compare difference in mean values between the two groups. Chi-square test was used for categorical variables. Paired t-test has been used for within group analysis. For every outcome variable, results are presented as mean \pm SD (Standard Deviation), p value $<0.05$ was considered statistically significant. STATA 12.0 (STATA Corp, Houston, TX, USA) statistical software has been used for data analysis.

\section{Result}

Demographical characteristics were almost similar in active and control group. Average age was $61 \pm 6$ years and $71(59 \%)$ patients were male.

Subjects with essential hypertension also having high mean serum uric acid of $6.8 \pm .2 \mathrm{mg} / \mathrm{dl}$ where as it was normal i.e. $4.2 \pm 0.2 \mathrm{mg} / \mathrm{dl}$ with control subjects who were not having any grade of hypertension $(\mathrm{p} \leq 0.005)$. (Figure 1$)$. 
Figure 1: Mean Serum Uric acid Levels in hypertensive and normotensive subjects

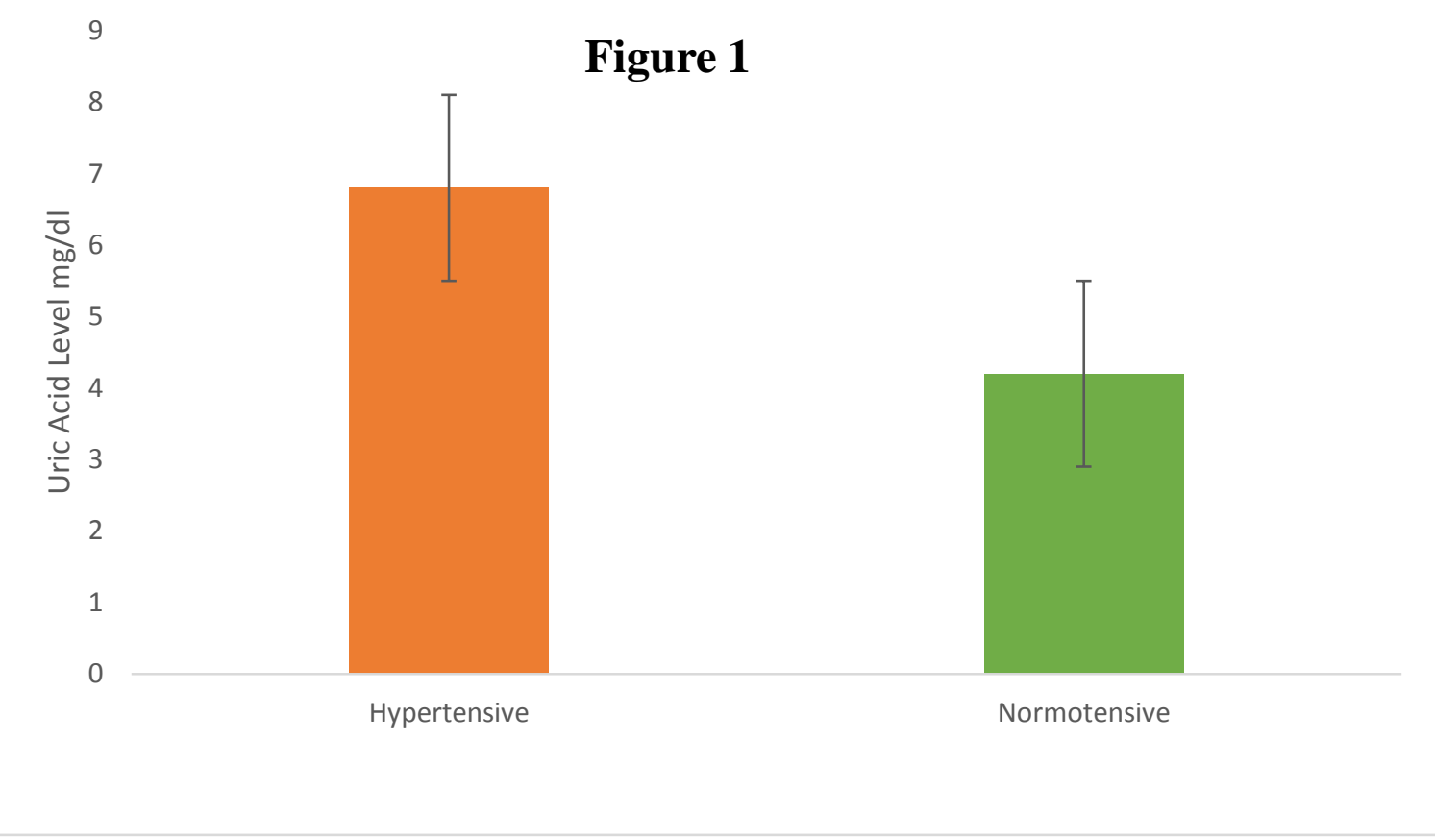

It was observed that even duration of HTN is effect the level of serum uric acid. Subjects who were having HTN for more than 5 years were having serum uric acid of $7.1 \pm 0.3 \mathrm{mg} / \mathrm{dl}$ whereas subjects who were having HTN for less than 5 years were having serum uric acid of $4.5 \pm 0.2$ $\mathrm{mg} / \mathrm{dl}$. (Figure 2)

Figure 2: Mean Serum Uric acid Levels in $<5$ YRS \&>5 YRS Duration after diagnosis of Hypertension (HTN)

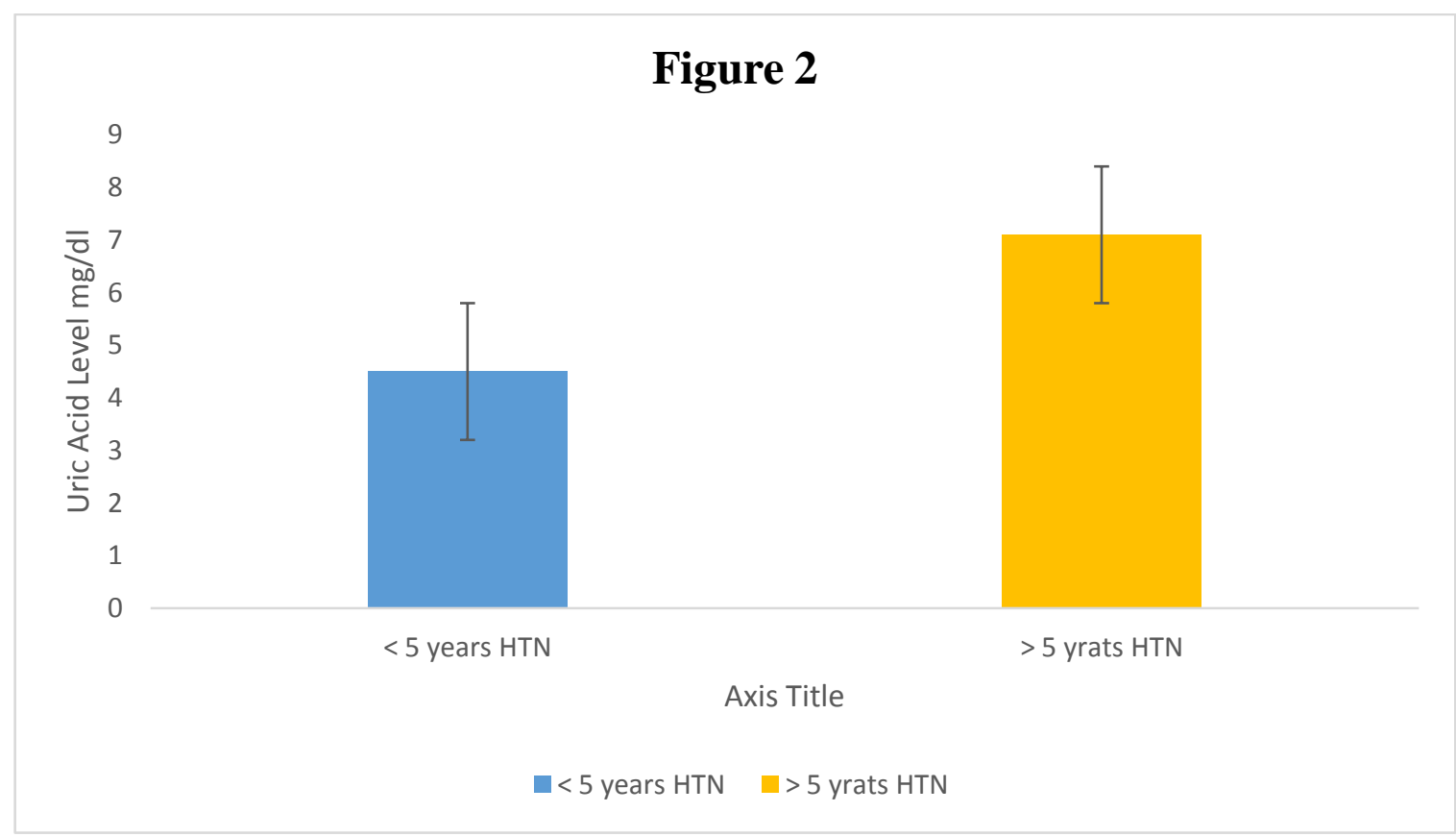

\section{Discussion}

Increased risk of cardiovascular (CV) disease is associated with increased serum uric acid level. By increased enhanced platelet aggregation and inflammatory activation of the endothelium increased serum uric acid may affect the cardio vascular system and structure ${ }^{[11]}$. Increased serum uric acid levels correlates with several risk factors 
including renal dysfunction, hypertension, insulin resistance, hyper-homocystenemia and hyperlipedemia, it is debated whether serum uric acid is an independent cardiovascular risk factor [12-14]. Than higher amount of serum creatinine presence in blood aggravate free radical production which increased oxidative stress and there for led to inhibition of endothelium dependent vasodilation.

As extensively reviewed by Puig and Ruilope, ${ }^{[15]}$ both uric acid and superoxide radicals are produced for the effect of xanthine oxidase in the late phase of purine metabolism. Superoxide radicals, which may cause tissue and vascular damage, ${ }^{[16]}$ are increased in subjects with essential hypertension $^{[17]}$.

Levels of other markers such as BNP, cardiac troponins, and markers of collagen turnover, are altered in the event of cardiac damage, which is independent of $\operatorname{HTN}^{[18,19]}$. However, measurement of all these markers has little value at present to justify their use in routine clinical practice over the use of the traditional screening methods, BP measurement, assessment of other risk factors, EKGs and ECHOs ${ }^{[20]}$.

In this observational study it has clearly demonstrated that high prevalence of serum uric acid is correlated to uncontrolled hypertension. Subjects with essential hypertension also having high mean serum uric acid of $6.8 \pm .2 \mathrm{mg} / \mathrm{dl}$ where as it was normal i.e. $4.2 \pm 0.2 \mathrm{mg} / \mathrm{dl}$ with control subjects who were not having any grade of hypertension ( $\mathrm{p} \leq 0.005)$. It was observed that even duration of HTN is effect the level of serum uric acid. Subjects who were having HTN for more than 5 years were having serum uric acid of $7.1 \pm 0.3 \mathrm{mg} / \mathrm{dl}$ whereas subjects who were having HTN for less than 5 years were having serum uric acid of $4.5 \pm 0.2 \mathrm{mg} / \mathrm{dl}$.

Serum uric acid levels with duration and severity of blood pressure there was a correlation. Breckenridge in his study showed an increasing incidence of hyperuricemia as the diastolic BP was shown increased in his study, but there was no tendency for hyperuricemia to occur, only with patients with more severe hypertension ${ }^{[21]}$.

\section{Conclusion}

Essential hypertension is a major risk factor for peripheral vascular disease, stroke, renal disease, CAD and heart failure. Hypertension is still diagnosed by conventional BP readings. Correlation between high serum uric acid and increased blood pressure has been established by this trial. The study has concluded that Serum uric acid can be used as a biomarker to detect essential hypertension severity and duration.

Conflicts of Interest: The authors have no conflicts of interest to declare.

\section{Reference}

1. Lim SS, Vos T, Flaxman AD, Danaei G, Shibuya K, Adair-Rohani $\mathrm{H}$, et al. A comparative risk assessment of burden of disease and injury attributable to 67 risk factors and risk factor clusters in 21 regions, 1990-2010: a systematic analysis for the Global Burden of Disease Study 2010. Lancet 2012; 380:2224-2260.

2. Leeder S, Raymond S, Greenberg H, Liu $\mathrm{H}$. A race against time. The challenge of cardiovascular disease in developing economies. New York:Columbia University; 2004

3. Srinath Reddy K, Shah B, Varghese C, Ramadoss A. Responding to the threat of chronic diseases in India. Lancet 2005; 366:1744-1749.

4. Gupta R. Trends in hypertension epidemiology in India. J Hum Hypertens 2004; 18:73-78.

5. Mackay J, Mensah G. Atlas of heart disease and stroke. Geneva:World Health Organization; 2004.

6. Kearney PM, Whelton M, Reynolds K, Muntner P, Whelton PK, He J. Global burden of hypertension: analysis of 
worldwide data. Lancet 2005 ; 365:217223

7. Strimbu K, Tavel JA. What are biomarkers? Curr Opin HIV AIDS 2010;5:463-6.

8. Dhawan V, Sharma I, Mahajan N, et al. Implication of Endothelin-2 and Oxidative Stress Biomarkers in Essential Hypertension. J Hypertension 2014;3: 1095-2167.

9. Julius S, Nesbitt SD, Egan BM, et al. Feasibility of treating prehypertension with an angiotensin-receptor blocker. N Engl J Med 2006;354:1685-97.

10. Lüders S, Schrader J, Berger J, et al. The PHARAO study: prevention of hypertension with the angiotensinconverting enzyme inhibitor ramipril in patients with high-normal blood pressure: a prospective, randomized, controlled prevention trial of the German Hypertension League. J Hypertens 2008;26:1487-96.

11. Kinsey D, Walther R, Sise HS, Whitelaw G, Smithwick R: Incidence of hyperuricemia in 400 hypertensive subjects. Circulation 1961; 24: 972-973.

12. Bonora E, Targher G, Zenere MB, Saggiani F, Cacciatori V, Tosi F, et al. Relationship of uric acid concentration to cardiovascular risk factors in young men. Role of obesity and central fat distribution. The Verona young men atherosclerosis risk factors study. Int $\mathrm{J}$ Obesity Relat Metab Disord 1996; 20: 975-980.

13. Malinow MR, Levenson J, Giral P, Nieto FJ, Razavian M, Segond P, et al. Role of blood pressure, uric acid, and hemorheological parameters on plasma homocyst(e)ine concentration. Atherosclerosis 1995; 114:175-183.
14. Woo J, Swaminathan R, Cockram C, Lau E, Chan A. Association between serum uric acid and some cardiovascular risk factors in a Chinese population. Postgrad Med J 1994; 70: 486-491.

15. Puig JG, Ruilope LM. "Uric acid as a cardiovascular risk factor in arterial hypertension." Journal of Hypertension. 1999; 17:869-872.

16. McCord JM. "Oxygen-derived free radicals in postischemic tissue injury". New England Journal of Medicine. 1985; 312:159-163.

17. Lacy F, O'Connor DT, SchmidSchoenbein GW. "Elevation in plasma hydrogen peroxide in hypertensive and normotensive subjects at genetic risk for hypertension". Journal of Hypertension. 1998; 16:292-303.

18. Takeda T, Kohno M. Brain natriuretic peptide in hypertension. Hypertens Res 1995; 18:259-66.

19. Tanindi A, Cemri M. Troponin elevation in conditions other than acute coronary syndromes. Vasc Health Risk Manag 2011;7:597-603.

20. Currie G, Delles C. Use of Biomarkers in the Evaluation and Treatment of Hypertensive Patients. CurrHypertens Rep 2016;18:54.

21. A. Breckenridge "Hypertension and Hyperuricemia" The Lancet 1966: 287;1518. 